\title{
Sistem Pendukung Keputusan Peminatan Jurusan Menggunakan Metode Topsis Pada SMA Negeri 1 Wonosari
}

\author{
Hamria ${ }^{1}$, Hamsir Saleh ${ }^{2}$
}

Teknik Informatika, Universitas Ichsan Gorontalo, JL. Drs. Achmad Nadjamuddin No 10, Kota Gorontalo

\begin{tabular}{|c|c|}
\hline Info Artikel & ABSTRAK \\
\hline Riwayat Artikel & $\begin{array}{l}\text { Sistem Pendukung Keputusan merupakan sistem yang dapat } \\
\text { membantu masalah yang teriadi untuk menentukan keputusan }\end{array}$ \\
\hline$\frac{\text { Riwayat Artikel }}{\text { Diterima: } 29-11-2020}$ & dengan cepat dan dapat mengetahui nilai tertinggi sampai \\
\hline Direvisi: $07-12-2020$ & terendah untuk hasil seleksi. Pada penelitian ini terdapat studi \\
\hline Disetujui: 22-12-2020 & $\begin{array}{l}\text { kasus yang merupakan contoh penyelesaian masalah dengan } \\
\text { sistem pendukung keputusan, dimana yang menjadi } \\
\text { permasalahan yaitu pada SMA Negeri } 1 \text { Wonosari tentang }\end{array}$ \\
\hline Kata Kunci & peminatan jurusan, meningkatnya jumlah siswa dari tahun ke \\
\hline Sistem Pendukung Keputusan; & tahun membuat pihak sekolah kewalahan dalam melakukan \\
\hline Peminatan Jurusan; & peminatan jurusan secara manual. Oleh karena itu dibutuhkan \\
\hline TOPSIS; & sebuah sistem pendukung keputusan yang dapat membantu \\
\hline SMA Negeri 1 Wonosari; & $\begin{array}{l}\text { peminatan jurusan. Penelitian ini bertujuan untuk merancang } \\
\text { dan menerapkan sistem pendukung keputusan peminatan } \\
\text { jurusan pada SMA Negeri } 1 \text { Wonosari menggunakan metode }\end{array}$ \\
\hline Corresponding Author & TOPSIS sebagai dasar pengambilan keputusan. Metode Topsis \\
\hline Hamria, & digunakan dalam penelitian ini karena metode TOPSIS \\
\hline Tel. +62 82292063211 & memiliki kemampuan untuk mengukur alternatif-alternatif \\
\hline hamriafatmawatihamka@unisan.ac.id & keputusan dalam bentuk matematis yang konsepnya sederhana \\
\hline & dan mudah untuk dipahami. Berdasarkan hasil penelitian yang \\
\hline & $\begin{array}{l}\text { pendukung keputusan peminatan jurusan pada SMA Negeri I } \\
\text { Wonosari menggunakan metode topsis yang sudah di rekayasa }\end{array}$ \\
\hline & $\begin{array}{l}\text { Wonosari menggunakan metode topsis yang sudah di rekayasa } \\
\text { dapat di implementasikan di SMA Negeri } 1 \text { Wonosari. Hal ini }\end{array}$ \\
\hline & dibuktikan melalui pengujian white box dan basis path yang \\
\hline & menghasilkan nilai $\mathrm{V}(\mathrm{G})=\mathrm{CC}$ dimana, $\mathrm{V}(\mathrm{G})=2$ dan $\mathrm{CC}=2$, \\
\hline & $\begin{array}{l}\text { sehingga didapat bahwa logika flowchart perhitungan } \\
\text { normalisasi dan perengkingan adalah benar dan penguijian }\end{array}$ \\
\hline & black box yang meliputi uji input proses dan output dengan \\
\hline & $\begin{array}{l}\text { mengacu pada rancangan perangkat lunak yang sudah di buat } \\
\text { telah terpenuhi sesuai dengan rancangan. }\end{array}$ \\
\hline
\end{tabular}

\section{PENDAHULUAN}

Pendidikan saat ini dapat mengembangkan potensi yang ada pada seseorang karena pendidikan memiliki peranan penting dalam menentukan kemajuan suatu bangsa dan masyarakat. Pendidikan harus selalu ditingkatkan dan dijaga mutunya karena pendidkan juga dianggap sebagai investasi jangka panjang yang dapat di manfaatkan dalam adaptasi dengan kehidupan nyata [1]. Semua pihak mengharapkan kehadiran sebuah lembaga pendidikan yang bermutu. Urgensi pengembangan mutu pendidikan dengan melihat pada kondisi realitas yang berkembang, tidak dapat ditunda lagi menurut Mukbulloh. Agar sejajar dengan kemajuan bangsa-bangsa dalam belahan dunia pendidikan di Indonesia perlu melakukan 
internasionalisasi mutu. Untuk meraih prestasi terbaik, diperlukan sistem manajemen mutu dalam pengembangan pendidikan [2]. Pada pendidikan formal di Indonesia jenjang pendidikan menengah SMA (Sekola Menengah Atas). Mulai dari kelas X Penjurusan di SMA Kurikulum 2013 tidak lagi dilakuan di kelas XI. Bagi pihak sekolah maupun pihak siswa, kebijakan ini merupakan tantangan dalam menerapkannya. Siswa belum dapat memastikan jurusan yang diinginkan, hal ini disebabkan karena kebanyakan belum sepenuhnya memahami dan mengeksplorasi mata pelajaran di tingkat SMA.

SMA Negeri 1 Wonosari telah menerapkan Kurikulum 2013 sejak tahun 2017, peminatan pada tingkat Sekolah Menengah Atas dilakukan sejak dini, yaitu sejak awal masuk pada kelas $X$. Peminatan di tingkat SMA Negeri 1 Wonosari dibagi 2 peminatan yaitu IPA dan IPS. Peminatan peserta didik pada SMA Negeri 1 Wonosari dilakukan dengan proses seleksi, ada beberapa tahap seleksi yang dilakukan diantaranya : nilai rapor SMP semester 1 sampai dengan 6 , nilai ujian nasional, wawancara, minat dan bakat. Berdasarkan hasil tes akademik setiap siswa, Wakasek bagian Kurikulum serta Guru BK melihat dan menghitung serta mempertimbangkan nilai raport, nilai Ujian Nasional dan nilai tes akademik masing-masing siswa sebagai salah satu proses peminatan. Tetapi, dalam melakukan proses peminatan tersebut tentu akan mengalami kendala karena meningkatnya jumlah siswa dari tahun ke tahun dan banyak kriteria yang digunakan untuk menentukan peminatan siswa yang nantinya digunakan untuk melakukan penilaian bakat/minat yang sesuai dengan keinginan siswa. Untuk memaksimalkan proses peminatan ini maka diperlukan suatu sistem pendukung keputusan sebagai solusi dalam menentukan peminatan.

Dalam mengambil keputusan pemilihan jurusan yang tepat dalam permasalahan diatas maka dibutuhkan suatu sistem yang dapat membantu siswa tersebut. Karena mampu memilih alternatif terbaik dari sejumlah alternatif Sistem Pendukung Keputusan Pemilihan Laptop Dengan Metode Topsis ini dipilih Menurut [3] dalam jurnalnya. Metode TOPSIS ini dapat mengurutkan nilai alternatif dari yang terkecil hingga yang terbesar berdasarkan hasil dari proses pengimplementasian agar laptop yang direkomendasikan diharapakan dapat sesuai dengan kebutuhan, kemampuan dan keinginan konsumen.

Beberapa penelitian yang telah dilakukan oleh para peneliti lain yang berhubungan dengan judul sistem pendukung keputusan peminatan jurusan pada SMA Negeri 1 Wonosari menggunakan metode Topsis adalah : (1) [3]dengan judul Sistem Pendukung Keputusan Pemilihan Laptop Dengan Metode Topsis menjelaskan bahwa ia memilih metode ini karena mampu memilih alternatif terbaik dari sejumlah alternatif Sistem Pendukung Keputusan Pemilihan Laptop Dengan Metode Topsis ini dipilih. Metode TOPSIS ini dapat mengurutkan nilai alternatif dari yang terkecil hingga yang terbesar berdasarkan hasil dari proses pengimplementasian agar laptop yang direkomendasikan diharapakan dapat sesuai dengan kebutuhan, kemampuan dan keinginan konsumen. (2) [4] dengan judul penelitiannya yaitu Implementasi Sistem Pendukung Keputusan Peminatan Peserta Didik SMA menggunakan Metode AHP (Analitic Hierarchy Process) dan SAW (Simple Additive Weighting) menjelaskan bahwa sistem ini membantu mempermudah dan memberikan rekomendasi dalam pelaksanaan peminatan peserta didik SMA yang sebelumnya dilakukan secara mnual dan metode Analytic Hierarchy Process (AHP) dan Simple Additive Weighting (SAW) dapat diterapkan pada system pendukung keputusan penetapan peminatan peserta didik SMA untuk memberikan alternative hasil perangkingan dan penentuan sebuah alternatif yg memiliki preferensi terbaik dari alterntif yang lain.

SPK dimaksud akan dibangun dengan menggunakan bahasa pemrograman PHP dan database MySQL Server, yang pada dasarnya aplikasi ini terdiri atas data siswa, kriteria penilaian, Alternatif Penilaian, Hasil Penilaian, dan seterusnya. Metode yang akan digunakan dalam sistem pendukung keputusan ini adalah TOPSIS. Berdasarkan nilai preferensi untuk mencari solusi ideal adalah metode TOPSIS (Technique For Order Preference By Similarity to 
Ideal Solution). Topsis menggunakan konsep berupa alternatif yang terpilih tidak hanya memiliki jarak terpanjang dari solusi ideal negatif namun juga memilik jarak terpendek dari solusi ideal positif sehingga menjadi alasan penggunaan metode ini. TOPSIS memiliki kemampuan untuk mengukur alternatif-alternatif keputusan dalam bentuk matematis karena konsepnya sederhana dan mudah untuk dipahami. Tujuan penelitian ini yaitu bagaimana merancang Sistem Pendukung Keputusan untuk membantu siswa SMA Negeri 1 Wonosari dalam Peminatan Jurusan menggunakan Metode TOPSIS.

\section{METODE}

\section{Pengumpulan Data}

Pengumpulan data dalam penelitian ini dilakukan dengan beberapa metode diantaranya metode observasi, wawancara serta pengumpulan data primer mengenai sistem yang diusulkan. SMA Negeri 1 Wonosari memiliki dua peminatan jurusan yaitu Ilmu Pengetahuan Alam (IPA) dan Ilmu Pengetahuan Sosial (IPS) yang dilakukan sejak dini yaitu sejak awal masuk kelas X. Jumlah siswa yang ada di SMA Negeri 1 Wonosari dari kelas X sampai XII yaitu 409 siswa. Berikut sampel data yang didapatkan dari SMA Negeri 1 Wonosari.

Tabel 1. Sampel Hasil Pengumpulan Data

\begin{tabular}{|c|l|c|c|c|c|c|c|}
\hline \multirow{2}{*}{ No } & \multirow{2}{*}{ Nama } & \multicolumn{2}{|c|}{$\begin{array}{c}\text { Nilai Raport } \\
\text { Semester 1 - 6 }\end{array}$} & \multicolumn{2}{c|}{ Nilai UN } & \multirow{2}{*}{$\begin{array}{c}\text { Minat dan } \\
\text { Bakat }\end{array}$} & $\begin{array}{c}\text { Hasil } \\
\text { Wawancara }\end{array}$ \\
\cline { 3 - 6 } & & IPA & IPS & IPA & IPS & & \\
\hline 1 & Eko Kartiko & 79 & 80 & 55 & 57 & 85 & 90 \\
\hline 2 & Lia Irmawaty & 82 & 84 & 30 & 32 & 75 & 85 \\
\hline 3 & Nopita Sari Rusdi & 87 & 88 & 68 & 68 & 83 & 70 \\
\hline 4 & Rivaldi Kadir & 86 & 83 & 40 & 39 & 87 & 75 \\
\hline 5 & Wulan Ruftiani & 93 & 94 & 67 & 69 & 90 & 84 \\
\hline
\end{tabular}

\section{Pemodelan Sistem}

Sistem adalah elemen-elemen yang saling berhubungan dan membentuk satu kesatuan atau organisasi. Model adalah Representasi dari sebuah obyek atau situasi actual.

\section{Menentukan Kriteria, Bobot, dan Alternatif}

Dalam metode TOPSIS terdapat kriteria-kriteria yang akan dijadikan bahan perhitungan hasil proses. Hal ini dimaksudkan untuk menentukan hasil proses peminatan jurusan pada SMA. Berikut kriteria, bobot, dan alternatif yang digunakan.

Tabel 2. Kriteria

\begin{tabular}{|c|c|l|}
\hline No & Kriteria & \multicolumn{1}{|c|}{ Keterangan Kriteria } \\
\hline 1 & C1 & Nilai Raport semester 1 -6 IPA \\
\hline 2 & C2 & Nilai Raport semester 1 -6 IPS \\
\hline 3 & C3 & Nilai Ujian Nasional IPA \\
\hline 4 & C4 & Nilai Ujian Nasional IPS \\
\hline 5 & C5 & Minat dan Bakat \\
\hline 6 & C6 & Hasil Wawancara \\
\hline
\end{tabular}

Tabel 3. Pembobotan

\begin{tabular}{|l|c|}
\hline \multicolumn{1}{|c|}{ Bobot } & Nilai Bobot \\
\hline Sangat Tinggi & 5 \\
\hline Tinggi & 4 \\
\hline Cukup & 3 \\
\hline Rendah & 2 \\
\hline Sangat Rendah & 1 \\
\hline
\end{tabular}


Tabel 4. Alternatif

\begin{tabular}{|c|c|l|l|l|}
\hline No & Alternatif & \multicolumn{1}{|c|}{ Nama } & \multicolumn{1}{|c|}{ Alamat } & J.Kelamin \\
\hline 1 & A1 & Eko Kartiko & Desa Harapan & Laki-laki \\
\hline 2 & A2 & Lia Irmawaty & Desa Dimito & Perempuan \\
\hline 3 & A3 & Nopita Sari Rusdi & Desa Harapan & Perempuan \\
\hline 4 & A4 & Rivaldi Kadir & Desa Harapan & Laki-laki \\
\hline 5 & A5 & Wulan Ruftiani & Desa Harapan & Perempuan \\
\hline
\end{tabular}

\section{Penerapan Metode TOPSIS}

1. Menetukan jenis-jenis kriteria

Adapun kriteria-kriteria yang digunakan dalam proses peminatan jurusan pada SMA dengan menggunakan TOPSIS yaitu:
a. Kriteria 1 : C1 : Nilai Raport Semester 1 - 6 IPA
b. Kriteria 2 : C2 : Nilai Raport Semester $1-6$ IPS
c. Kriteria 3 : C3 : Nilai Ujian Nasional IPA
d. Kriteria 4 : C4 : Nilai Ujian Nasional IPS
e. Kriteria 5: C5 : Minat Dan Bakat
f. Kriteria 6: C6 : Wawancara

2. Menentukan bobot preferensi untuk setiap kriteria

Nilai bobot dari pereferensi tiap-tiap kriteria yaitu sebagai berikut:
a. C1 : Nilai Raport Semester 1-6 IPA $: 4$
b. C2: Nilai Raport Semester 1 - 6 IPS : 4
c. C3: Nilai Ujian Nasional IPA : 4
d. C4: Nilai Ujian Nasional IPS :4
e. C5: Minat Dan Bakat : 5
f. C6: Wawancara :5

Penentuan nilai bobot preferensi untuk setiap kriteria ini diberikan berdasarkan nilai bobot yang telah ditentukan pada tabel 5 .

Tabel 5. Matriks Keputusan

\begin{tabular}{|c|c|c|c|c|c|c|}
\hline \multirow{2}{*}{ Alternatif } & \multicolumn{7}{|c|}{ Kriteria } \\
\cline { 2 - 7 } & C1 & C2 & C3 & C4 & C5 & C6 \\
\hline A1 & 79 & 80 & 55 & 57 & 85 & 90 \\
\hline A2 & 82 & 84 & 30 & 32 & 75 & 85 \\
\hline A3 & 87 & 88 & 68 & 68 & 83 & 70 \\
\hline A4 & 86 & 83 & 40 & 39 & 87 & 75 \\
\hline A5 & 93 & 94 & 67 & 69 & 90 & 84 \\
\hline
\end{tabular}

Penentuan nilai pada matriks keputusan didapatkan dari hasil pengumpulan data yang didapatkan dari lokasi penelitian.

Setelah membentuk matriks keputusan, selajutnya menormalisasi nilai matriks keputusan sebagai berikut [5]:

$$
r_{i j}=\frac{X_{i j}}{\sqrt{\sum_{i=1}^{m} X_{i j}^{2}}} \quad \text { - Persamaan (1) }
$$

Dimana :

$r_{i j}=$ Hasil dari normalisasi matriks keputusan $\mathrm{R}$

$X_{i j}=$ Matriks keputusan

I $=1,2,3, \ldots, \mathrm{m}$;

$\mathrm{J}=1,2,3, \ldots, \mathrm{m}$;

Dari rumus diatas maka dapat di nilai dari setiap alternatif terhadap masing - masing kriteria yaitu :

$$
\left|X_{1}\right|=\sqrt{79^{2}+83^{2}+87^{2}+86^{2}+93^{2}}=191,2563724
$$




$$
\begin{aligned}
& r_{11}=\frac{79}{191,2563724}=0,413058132 \\
& r_{12}=\frac{82}{191,2563724}=0,428743884 \\
& r_{13}=\frac{87}{191,2563724}=0,454886804 \\
& r_{14}=\frac{86}{191,2563724}=0,44965822 \\
& r_{15}=\frac{93}{191,2563724}=0,486258308 \\
& \left|X_{2}\right|=\sqrt{80^{2}+84^{2}+88^{2}+83^{2}+94^{2}}=192,1587885 \\
& r_{16}=\frac{80}{192,1587885}=0,416322358 \\
& r_{17}=\frac{84}{192,1587885}=0,437138476 \\
& r_{18}=\frac{88}{192,1587885}=0,457954594 \\
& r_{19}=\frac{83}{192,1587885}=0,431934447 \\
& r_{20}=\frac{94}{192,1587885}=0,489178771 \\
& \left|X_{3}\right|=\sqrt{55^{2}+30^{2}+68^{2}+40^{2}+67^{2}}=120,9876027 \\
& r_{21}=\frac{55}{120,9876027}=0,454592031 \\
& r_{22}=\frac{30}{120,9876027}=0,24795929 \\
& r_{23}=\frac{68}{120,9876027}=0,562041056 \\
& r_{24}=\frac{40}{120,9876027}=0,330612386 \\
& r_{25}=\frac{67}{120,9876027}=0,553775747 \\
& \left|X_{4}\right|=\sqrt{57^{2}+32^{2}+68^{2}+39^{2}+69^{2}}=123,2030844 \\
& r_{26}=\frac{57}{123,2030844}=0,462650755 \\
& r_{27}=\frac{32}{123,2030844}=0,259733757 \\
& r_{28}=\frac{68}{123,2030844}=0,551934234 \\
& r_{29}=\frac{39}{123,2030844}=0,316550517 \\
& r_{30}=\frac{69}{123,2030844}=0,560050914 \\
& \left|X_{5}\right|=\sqrt{85^{2}+75^{2}+83^{2}+87^{2}+90^{2}}=188,1701358 \\
& r_{31}=\frac{85}{188,1701358}=0,451718864 \\
& r_{32}=\frac{75}{188,1701358}=0,398575468 \\
& r_{33}=\frac{83}{188,1701358}=0,441090185 \\
& r_{34}=\frac{87}{188,1701358}=0,462347543 \\
& r_{35}=\frac{90}{188,1701358}=0,478290562 \\
& \left|X_{6}\right|=\sqrt{90^{2}+85^{2}+70^{2}+75^{2}+84^{2}}=181,4001103 \\
& r_{36}=\frac{90}{181,4001103}=0,496140823 \\
& r_{37}=\frac{85}{181,4001103}=0,468577444 \\
& r_{38}=\frac{70}{181,4001103}=0,385887307
\end{aligned}
$$




$$
\begin{aligned}
& r_{39}=\frac{75}{181,4001103}=0,413450686 \\
& r_{40}=\frac{84}{181,4001103}=0,463064768
\end{aligned}
$$

Setelah di dapat nilai kriteria dari setiap alternatif yang terdapat pada matriks keputusan, maka di proleh matriks ternormalisasi $\mathrm{R}$ yaitu sebagai berikut:

Tabel 6. Matriks Normalisasi

\begin{tabular}{|c|l|l|l|l|l|c|}
\hline \multirow{2}{*}{$\begin{array}{c}\text { Alter } \\
\text { natif }\end{array}$} & \multicolumn{1}{|c|}{ C1 } & \multicolumn{1}{|c|}{ C2 } & \multicolumn{1}{|c|}{ C3 } & \multicolumn{1}{c|}{ C4 } & C5 & C6 \\
\hline A1 & 0,413058132 & 0,416322358 & 0,454592031 & 0,462650755 & 0,451718864 & 0,496140823 \\
\hline A2 & 0,428743884 & 0,437138476 & 0,24795929 & 0,259733757 & 0,398575468 & 0,468577444 \\
\hline A3 & 0,454886804 & 0,457954594 & 0,562041056 & 0,551934234 & 0,441090185 & 0,385887307 \\
\hline A4 & 0,44965822 & 0,431934447 & 0,330612386 & 0,316550517 & 0,462347543 & 0,413450686 \\
\hline A5 & 0,486258308 & 0,489178771 & 0,553775747 & 0,560050914 & 0,478290562 & 0,463064768 \\
\hline
\end{tabular}

Setelah memproleh matriks normalisasi, selanjutnya nilai dikalikan dengan nilai bobot preferensi pada setiap kriteria.

Kriteria ke-1

$$
\begin{aligned}
& y_{11}=4 \times 0,413058132=1,652232529 \\
& y_{12}=4 \times 0,428743884=1,714975537 \\
& y_{13}=4 \times 0,454886804=1,819547216 \\
& y_{14}=4 \times 0,44965822=1,79863288 \\
& y_{15}=4 \times 0,486258308=1,945033231 \\
& \text { Kriteria ke-3 } \\
& y_{31}=4 \times 0,454592031=1,818368123 \\
& y_{32}=4 \times 0,24795929=0,991837158 \\
& y_{33}=4 \times 0,562041056=2,248164225 \\
& y_{34}=4 \times 0,330612386=1,322449544 \\
& y_{35}=4 \times 0,553775747=2,215102986 \\
& \text { Kriteria ke-5 } \\
& y_{51}=5 \times 0,451718864=2,258594321 \\
& y_{52}=5 \times 0,398575468=1,992877342 \\
& y_{53}=5 \times 0,441090185=2,205450925 \\
& y_{54}=5 \times 0,462347543=2,311737716 \\
& y_{55}=5 \times 0,478290562=2,39145281
\end{aligned}
$$

Kriteria ke-2

$y_{21}=4 \times 0,416322358=1,665289433$

$y_{22}=4 \times 0,437138476=1,748553905$

$y_{23}=4 \times 0,457954594=1,831818377$

$y_{24}=4 \times 0,431934447=1,727737787$

$y_{25}=4 \times 0,489178771=1,956715084$

Kriteria ke-4

$y_{41}=4 \times 0,462650755=1,85060302$

$y_{42}=4 \times 0,259733757=1,038935029$

$y_{43}=4 \times 0,551934234=2,207736936$

$y_{44}=4 \times 0,316550517=1,266202066$

$y_{45}=4 \times 0,560050914=2,240203656$

Kriteria ke-6

$y_{61}=5 \times 0,496140823=2,480704115$

$y_{62}=5 \times 0,468577444=2,34288722$

$y_{63}=5 \times 0,385887307=1,929436534$

$y_{64}=5 \times 0,413450686=2,067253429$

$y_{65}=5 \times 0,463064768=2,315323841$

Tabel 7. Matriks Normalisasi Terbobot (Y)

\begin{tabular}{|c|l|c|c|c|c|c|}
\hline \multirow{2}{*}{$\begin{array}{c}\text { Alter } \\
\text { natif }\end{array}$} & \multicolumn{7}{|c|}{ C1 } & C2 & C3 & C4 & C5 & C6 \\
\hline A1 & 1,652232529 & 1,665289433 & 1,818368123 & 1,85060302 & 2,258594321 & 2,480704115 \\
\hline A2 & 1,714975537 & 1,748553905 & 0,991837158 & 1,038935029 & 1,992877342 & 2,34288722 \\
\hline A3 & 1,819547216 & 1,831818377 & 2,248164225 & 2,207736936 & 2,205450925 & 1,929436534 \\
\hline A4 & 1,79863288 & 1,727737787 & 1,322449544 & 1,266202066 & 2,311737716 & 2,067253429 \\
\hline A5 & 1,945033231 & 1,956715084 & 2,215102986 & 2,240203656 & 2,39145281 & 2,315323841 \\
\hline
\end{tabular}

3. Menentukan Nilai Solusi Ideal

Setelah memproleh nilai perkalian matriks normalisasi dengan nilai preferensi, maka tahap selanjutnya adalah menentukan nilai solusi ideal positif dan nilai solusi ideal negatif dengan cara menentukan nilai terendah dan tertinggi dari setiap kriteria pada matiks normalisasi terbobot.

$$
Y_{j}^{+}=\text {nilai max dari } Y_{i j} \quad \text { - Persamaan (2) }
$$

$Y_{1}^{+}=\max \{1,652232529,1,714975537,1,819547216,1,79863288,1,945033231\}=1,945033231$

$Y_{2}^{+}=\max \{1,665289433,1,748553905,1,831818377,1,727737787,1,956715084\}=1,956715084$ 
$Y_{3}^{+}=\max \{1,818368123,0,991837158,2,248164225,1,322449544,2,215102986\}=2,248164225$

$Y_{4}^{+}=\max \{1,85060302,1,038935029,2,207736936,1,266202066,2,240203656\}=2,240203656$

$Y_{5}^{+}=\max \{2,258594321,1,992877342,2,205450925,2,311737716,2,39145281\}=2,39145281$

$Y_{6}^{+}=\max \{2,480704115,2,34288722,1,929436534,2,067253429,2,315323841\}=2,480704115$

Maka dapat diketahui nilai solusi ideal positif :

$A^{+}=\{1,945033231,1,956715084,2,248164225,2,240203656,2,39145281,2,480704115\}$

$Y_{j}^{-}=$nilai min dari $Y_{i j}$

$Y_{1}^{-}=\min \{1,652232529,1,714975537,1,819547216,1,79863288,1,945033231\}=1,652232529$

$Y_{2}^{-}=\min \{1,665289433,1,748553905,1,831818377,1,727737787,1,956715084\}=1,665289433$

$Y_{3}^{-}=\min \{1,818368123,0,991837158,2,248164225,1,322449544,2,215102986\}=0,991837158$

$Y_{4}^{-}=\min \{1,85060302,1,038935029,2,207736936,1,266202066,2,240203656\}=1,038935029$

$Y_{5}^{-}=\min \{2,258594321,1,992877342,2,205450925,2,311737716,2,39145281\}=1,992877342$

$Y_{6}^{-}=\min \{2,480704115,2,34288722,1,929436534,2,067253429,2,315323841\}=1,929436534$

Maka dapat diketahui nilai solusi ideal negatif :

$A^{-}=\{1,652232529,1,665289433,0,991837158,1,038935029,1,992877342,1,929436534\}$

4. Menghitung Separasi

a. Menghitung antara nilai normalisasi terbobot setiap alternatif terhadap solusi ideal positif yaitu sebagai berikut:

$$
D_{i}^{+}=\sqrt{\left(v_{I J}-v_{J}^{+}\right)^{2}}-\quad \text { Persamaan (3) }
$$

$$
\begin{aligned}
& (1,652232529-1,945033231)^{2}+(1,665289433-1,956715084)^{2}+ \\
& D_{1}^{+}=\sqrt{\begin{array}{c}
(1,6528368123-0,991837158)^{2}+(1,85060302-1,038935029)^{2}+ \\
(2,258594321-2,39145281)^{2}+(2,480704115-2,480704115)^{2}
\end{array}}=1,237041189 \\
& (1,714975537-1,945033231)^{2}+(1,748553905-1,956715084)^{2}+ \\
& D_{2}^{+}=(0,991837158-0,991837158)^{2}+(1,038935029-1,038935029)^{2}+ \\
& (1,992877342-2,39145281)^{2}+(2,34288722-2,480704115)^{2} \\
& D_{3}^{+}=\sqrt{\begin{array}{l}
(1,819547216-1,945033231)^{2}+(1,831818377-1,956715084)^{2}+ \\
(2,205464225-0,991837158)^{2}+(2,207736936-1,038935029)^{2}+
\end{array}} \\
& D_{+}^{+}=\sqrt{(1,79863288-1,945033231)^{2}+(1,727737787-1,956715084)^{2}+} \\
& D_{4}^{+}=\sqrt{\frac{(1,322449544-0,991837158)^{2}+(1,266202066-1,038935029)^{2}+}{(2,311737716-2,39145281)^{2}+(2,067253429-2,480704115)^{2}}} \\
& =0,523558516 \\
& =1,820520303 \\
& =0,641961437 \\
& D_{5}^{+}=\sqrt{\begin{array}{l}
(1,945033231-1,945033231)^{2}+(1,956715084-1,956715084)^{2}+ \\
(2,215102986-0,991837158)^{2}+(2,240203656-1,038935029)^{2}+ \\
(2,39145281-2,39145281)^{2}+(2,315323841-2,480704115)^{2}
\end{array}} \\
& =1,722433231
\end{aligned}
$$

b. Mengitung antara nilai normalisasi terbobot setiap alternatif terhadap solusi ideal negatif yaitu sebagai berikut :

$$
\left.D_{i}^{-}=\sqrt{\left(v_{I J}-v_{J}^{-}\right.}\right)^{2}
$$

$$
\begin{aligned}
& D_{1}^{-}=\sqrt{\begin{array}{ll}
\left(\begin{array}{l}
(, 652232529-1,652232529)^{2}+(1,665289433-1,665289433)^{2}+ \\
(1,818368123-2,248164225)^{2}+(1,85060302-2,240203656)^{2}+
\end{array}\right. & =0,843216937 \\
(2,258594321-1,992877342)^{2}+(2,480704115-1,929436534)^{2} &
\end{array}} \\
& D_{2}^{-}=\sqrt{\begin{array}{l}
(1,714975537-1,652232529)^{2}+(1,748553905-1,665289433)^{2}+ \\
(0,991837158-2,248164225)^{2}+(1,038935029-2,240203656)^{2}+ \\
(1,992877342-1,992877342)^{2}+(2,34288722-1,929436534)^{2}
\end{array}}=1,789752815
\end{aligned}
$$




$$
\begin{aligned}
& D_{3}^{-}=\sqrt{\begin{array}{l}
(1,819547216-1,652232529)^{2}+(1,831818377-1,665289433)^{2}+ \\
(2,248164225-2,248164225)^{2}+(2,207736936-2,240203656)^{2}+ \\
(2,205450925-1,992877342)^{2}+(1,929436534-1,929436534)^{2}
\end{array}}=0,319323832 \\
& D_{4}^{-}=\sqrt{\begin{array}{c}
(1,79863288-1,652232529)^{2}+(1,727737787-1,665289433)^{2}+ \\
(1,322449544-2,248164225)^{2}+(1,266202066-2,240203656)^{2}+ \\
(2,311737716-1,992877342)^{2}+(2,067253429-1,929436534)^{2}
\end{array}}=1,397005748 \\
& D_{5}^{-}=\sqrt{\begin{array}{l}
(1,945033231-1,652232529)^{2}+(1,956715084-1,665289433)^{2}+ \\
(2,215102986-2,248164225)^{2}+(2,240203656-2,240203656)^{2}+ \\
(2,39145281-1,992877342)^{2}+(2,315323841-1,929436534)^{2}
\end{array}}=0,692477887
\end{aligned}
$$

5. Menghitumg jarak solusi idel positif $(D)$ dan jarak solusi ideal negatif $\left(D^{-}\right)$terhadap solusi ideal (v) dengan rumus:

$$
\begin{aligned}
& v_{i}=\frac{D_{i}^{-}}{D_{i}^{-}+D_{i}^{+}} \quad \text { - Persamaan (4) } \\
& v_{1}=\frac{0,843216937}{0,843216937+1,237041189}=0,405342456 \\
& v_{2}=\frac{1,789752815}{1,789752815+0,523558516}=0,773675722 \\
& v_{3}=\frac{0,319323832}{0,319323832+1,820520303}=0,149227613 \\
& v_{4}=\frac{1,397005748}{1,397005748+0,641961437}=0,68515362 \\
& v_{5}=\frac{0,692477887}{0,692477887+1,722433231}=0,286750879
\end{aligned}
$$

Membuat rangking dari hasil setiap alternatif

Tabel 8. Hasil Perhitungan Metode Topsis

\begin{tabular}{|c|l|l|c|c|}
\hline No & Nama Alternatif & Nilai Preferensi & Rangking & Hasil Seleksi \\
\hline 1 & Lia Irmawaty & 0,773675722 & 1 & IPA \\
\hline 2 & Rivaldi Kadir & 0,68515362 & 2 & IPA \\
\hline 3 & Eko Kartiko & 0,405342456 & 3 & IPS \\
\hline 4 & Wulan Ruftiani & 0,286750879 & 4 & IPS \\
\hline 5 & Nopita Sari Rusdi & 0,149227613 & 5 & IPS \\
\hline
\end{tabular}

Hasil penelitian ini mengenai sistem pendukung keputusan peminatan jurusan pada SMA Negeri 1 Wonosari antara bertujuan untuk membantu dalam peminatan jurusan IPA dan IPS. Dari nilai 0 - 0.5 ke atas masuk jurusan IPS dan 0.51 - 1.00 masuk jurusan IPA.

\section{SOFTWARE DEVELOPMENT}

a. Analisis Sistem

Berikut merupakan gambaran Analisis system yang diusulkan : 
b. Desain Sistem

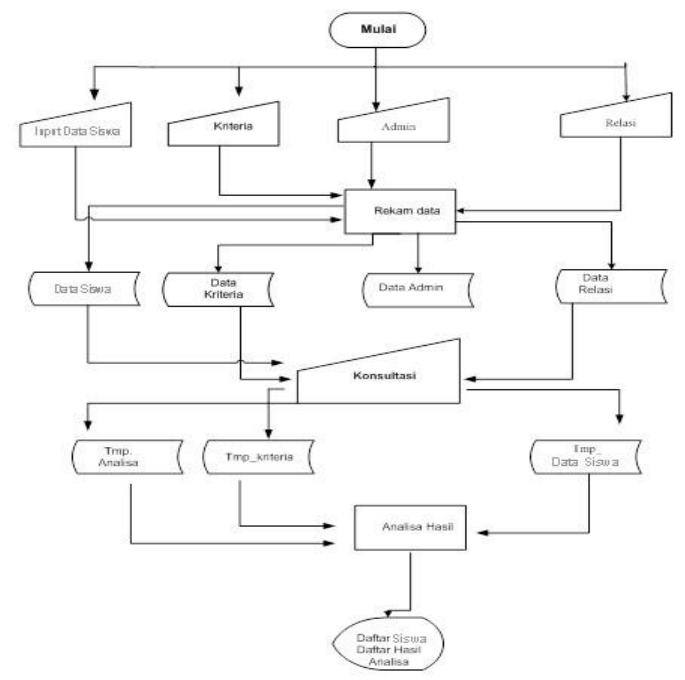

Gambar 1. Sistem Diusulkan

Diagram konteks pada penelitian ini terdiri atas 2 entitas yaitu entitas admin dan user. Admin adalah selaku atasan pemegang hak admin dan user hanya siswa yang di nilai.

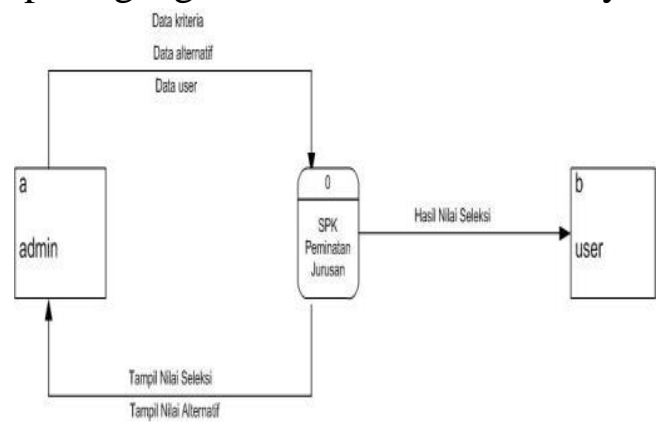

Gambar 2. Diagram Konteks

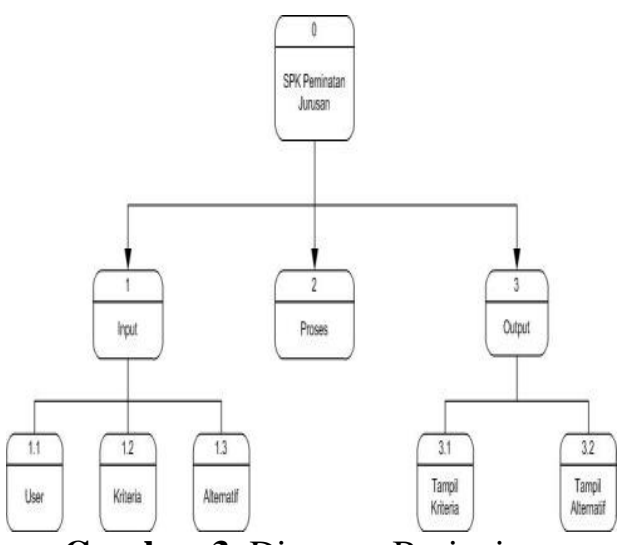

Gambar 3. Diagram Berjenjang 


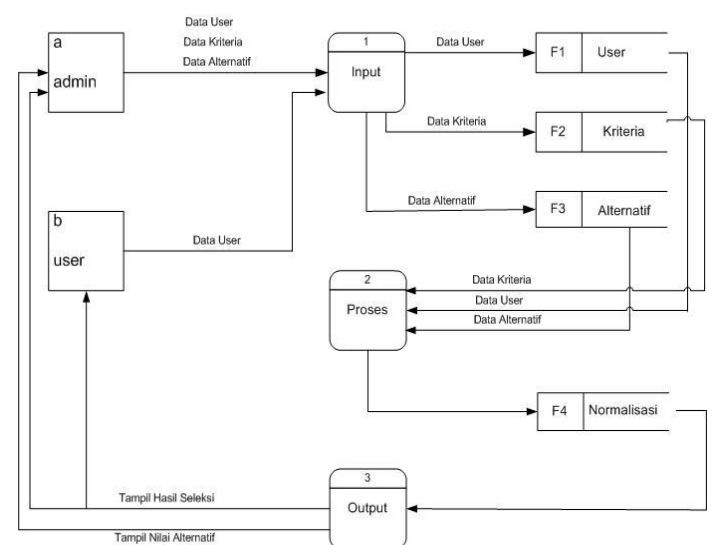

Gambar 4. DAD Level 0

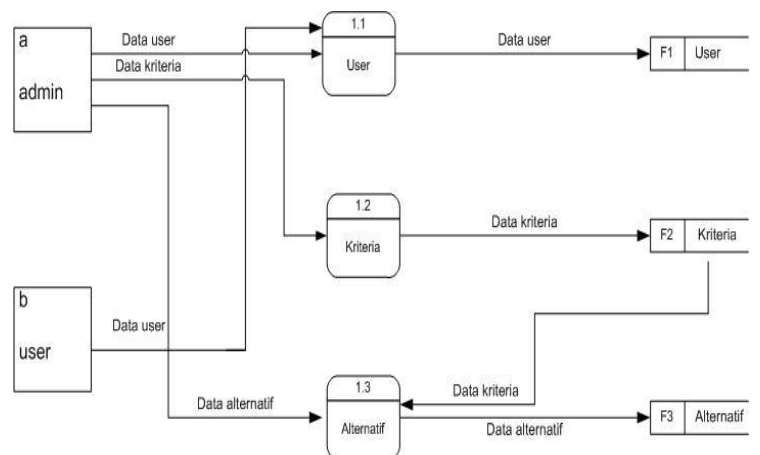

Gambar 5. DAD Level 1 Proses 1

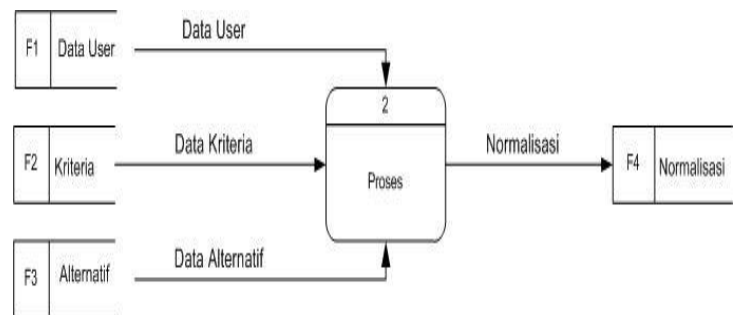

Gambar 6. DAD Level 1 Proses 2

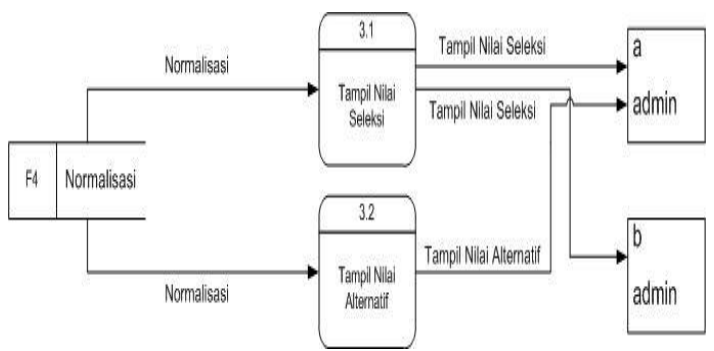

Gambar 7. DAD Level 1 proses 3

\section{HASIL DAN PEMBAHASAN}

Bahasa pemrograman yang digunakan dalam penelitian ini, yaitu menggunakan Bahasa Pemrograman PHP dan MySQL sebagai Databasenya. Aplikasi ini berarsitektur web namun tidak di posting ke internet, sehingga hanya berjalan di localhost/server saja dengan xampp sebagai server local dan chrome sebagari browser untuk menjalankan web. Berikut ini adalah langkah-langkah menjalankan sistem:

1. Buka browser (Google Chrome atau Mozila Firefox) 
2. Ketik URL: http:/localhost/topsis pada browser sehingga muncul tampilan sebagai berikut:

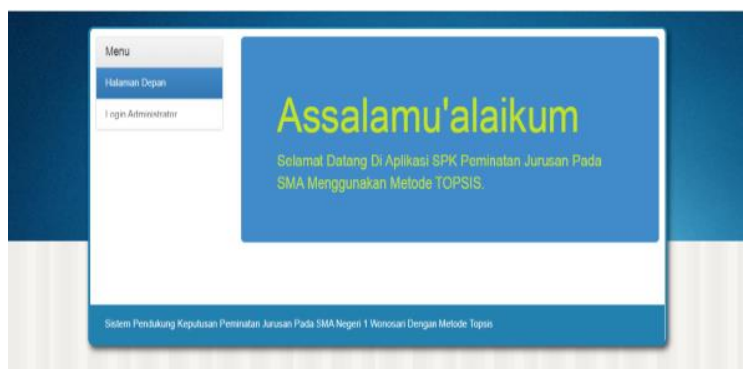

Gambar 8. Halaman Depan

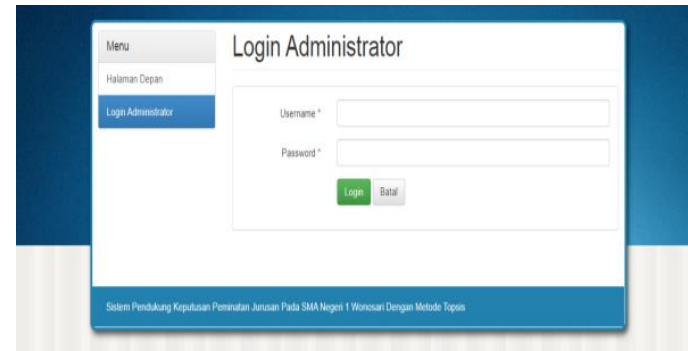

Gambar 9. Halaman Login Admin

Pada halaman login admin/user menginput username dan password agar bisa masuk ke dalam halaman aplikasi SPK tersebut.

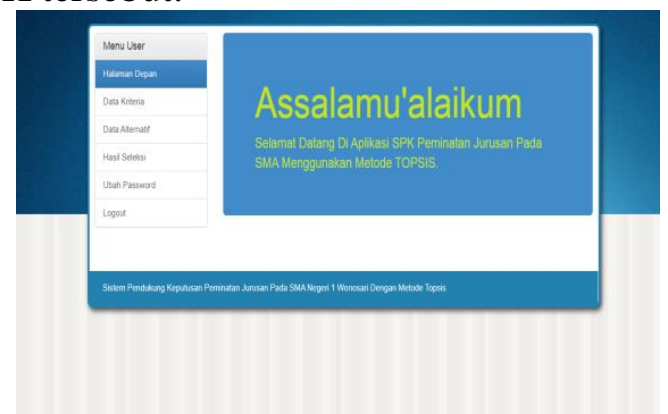

Gambar 10. Halaman Utama

Halaman ini berfungsi untuk menanmpilkan menu-menu yang ada pada aplikasi SPK.

Data Kriteria

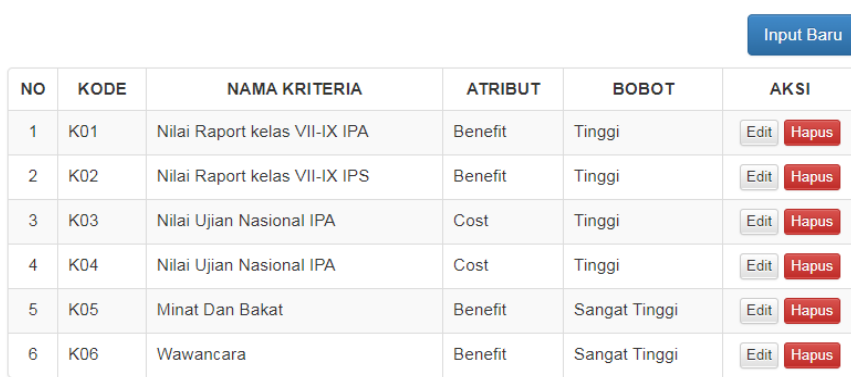

Gambar 11. Halaman Data Kriteria

Halaman menu kriteria menampilkan kriteria yang sudah di inputkan sedangkan untuk mengubah atau menambahkan nama kriteria,atribut dan bobot maka klik menu input baru. 


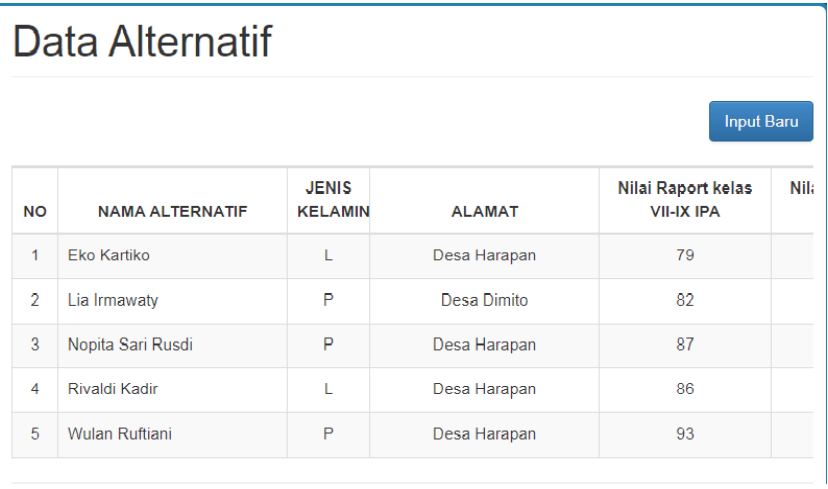

Gambar 12. Halaman Data Alternatif

Pada halaman menu alternatif ini menampilkan alternatif yang sudah di inputkan. Jika ingin mengubah atau menambahkan alternatif baru maka klik menu input baru yang ada di pojok kanan atas.

Halaman menu hasil seleksi menampilkan langkah-langkah perhitungan topsis.

Hasil Seleksi

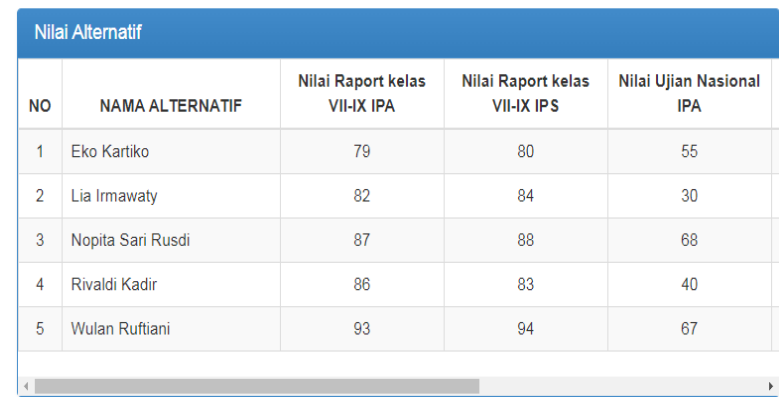

Gambar 13. Nilai Alternatif

\begin{tabular}{|c|c|c|c|c|c|c|c|}
\hline \multicolumn{2}{|c|}{ Normalisasi } \\
\hline No & NAMA ALTERNATIF & K01 & K02 & K03 & K04 & K05 & K06 \\
\hline 1 & Eko Kartiko & 0.41306 & 0.41632 & 0.45459 & 0.46265 & 0.45172 & 0.49614 \\
\hline 2 & Lia Irmawaty & 0.42874 & 0.43714 & 0.24796 & 0.25973 & 0.39858 & 0.46858 \\
\hline 3 & Nopita Sari Rusdi & 0.45489 & 0.45795 & 0.56204 & 0.55193 & 0.44109 & 0.38589 \\
\hline 4 & Rivaldi Kadir & 0.44966 & 0.43193 & 0.33061 & 0.31655 & 0.46235 & 0.41345 \\
\hline 5 & Wulan Ruftiani & 0.48626 & 0.48918 & 0.55378 & 0.56005 & 0.47829 & 0.46306 \\
\hline & & & & & & & \\
\hline
\end{tabular}

Gambar 14. Normalisasi

\begin{tabular}{|c|c|c|c|c|c|c|c|c|}
\hline \multicolumn{2}{|l}{ Normalisai Terbobot } \\
\hline NO & NAMA ALTERNATIF & K01 & K02 & K03 & K04 & K05 & K06 \\
\hline 1 & Eko Kartiko & 1.65224 & 1.66528 & 1.81836 & 1.8506 & 2.2586 & 2.4807 \\
\hline 2 & Lia Irmawaty & 1.71496 & 1.74856 & 0.99184 & 1.03892 & 1.9929 & 2.3429 \\
\hline 3 & Nopita Sari Rusdi & 1.81956 & 1.8318 & 2.24816 & 2.20772 & 2.20545 & 1.92945 \\
\hline 4 & Rivaldi Kadir & 1.79864 & 1.72772 & 1.32244 & 1.2662 & 2.31175 & 2.06725 \\
\hline 5 & Wulan Ruftiani & 1.94504 & 1.95672 & 2.21512 & 2.2402 & 2.39145 & 2.3153 \\
\hline & & & & & & & \\
\hline
\end{tabular}

Gambar 15. Normalisasi Terbobot 


\section{Matiks Solusi ldeal Positif}

\begin{tabular}{|c|c|c|c|c|c|}
\hline KO1 & K02 & KO3 & KO4 & K05 & KO6 \\
\hline 1.94504 & 1.95672 & 2.24816 & 2.2402 & 2.39145 & 2.4807 \\
\hline
\end{tabular}

Gambar 16. Matriks Solusi Ideal Positif

\section{Matriks Solusi Ideal Negatif}

\begin{tabular}{|c|c|c|c|c|c|}
\hline K01 & K02 & K03 & K04 & K05 & K06 \\
\hline 1.65224 & 1.66528 & 0.99184 & 1.03892 & 1.9929 & 1.92945 \\
\hline
\end{tabular}

Gambar 17. Matriks Solusi Ideal Negatif

\section{Jarak Solusi \& Nilai Preferensi}

\begin{tabular}{|c|c|c|c|c|}
\hline No & NAMA ALTERNATIF & $\begin{array}{l}\text { JARAK SOLUSI } \\
\text { IDEAL POSITIF ( } d+\text { ) }\end{array}$ & $\begin{array}{l}\text { JARAK SOLUSI } \\
\text { IDEAL NEGATIF (d-) }\end{array}$ & NILAI PREFERENSI \\
\hline 1 & Eko Kartiko & 1.23704 & 0.8432 & 0.40534 \\
\hline 2 & Lia Irmawaty & 0.52354 & 1.78976 & 0.77368 \\
\hline 3 & Nopita Sari Rusdi & 1.82051 & 0.31931 & 0.14922 \\
\hline 4 & Rivaldi Kadir & 0.64197 & 1.397 & 0.68515 \\
\hline 5 & Wulan Ruftiani & 1.72245 & 0.69245 & 0.28674 \\
\hline
\end{tabular}

Gambar 18. Jarak Solusi dan Nilai Preferensi

\begin{tabular}{|c|c|c|c|c|}
\hline \multicolumn{2}{|l|}{ Hasil Akhir } \\
\hline NO & NAMA ALTERNATIF & NILAI PREFERENSI & RANGKING & HASIL SELEKSI \\
\hline 1 & Lia lrmawaty & 0.77368 & 1 & IPA \\
\hline 2 & Rivaldi Kadir & 0.68515 & 2 & IPA \\
\hline 3 & Eko Kartiko & 0.40534 & 3 & IPS \\
\hline 4 & Wulan Ruftiani & 0.28674 & 4 & IPS \\
\hline 5 & Nopita Sari Rusdi & 0.14922 & 5 & IPS \\
\hline & & & & \\
\hline
\end{tabular}

Gambar 19. Hasil Akhir Topsis

Pada halaman ini menampilkan hasil perengkingan akhir dari perhitungan metode topsis.

Ubah Password

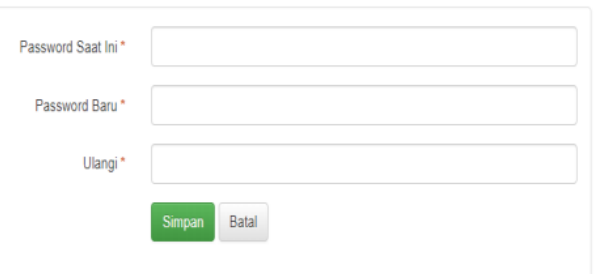

Gambar 20. Ubah Password 
Pada halaman ubah password ini admin/user bisa mengubah password yang lebih aman sesuai dengan keinginan admin/user.

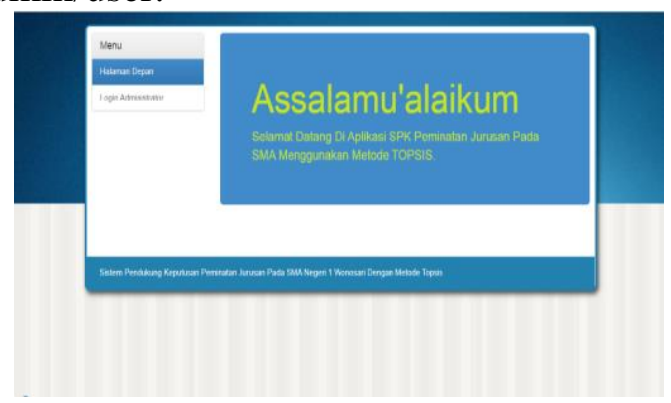

Gambar 21. Halaman Depan

Menu logout tidak mempunyai tampilan halaman menu tapi jika kita men klik menu logout maka otomatis di kembalikan di halaman depan.

\section{Pengujian Black Box}

Hasil pengujian black box dalam penelitian ini dapat dilihat pada tabel 9:

Tabel 9. Pengujian Black Box

\begin{tabular}{|c|c|c|c|c|}
\hline No & Input / Event & Fungsi & Hasil & Keterangan \\
\hline 1 & Login Admin & $\begin{array}{l}\text { Login dengan } \\
\text { menginputkan } \\
\text { username dan } \\
\text { password }\end{array}$ & $\begin{array}{l}\text { - Jika username atau password } \\
\text { salah maka ulangi menginput } \\
\text { username dan password } \\
\text { - Jika username dan password } \\
\text { benar maka diarahkan ke } \\
\text { halaman admin }\end{array}$ & Sesuai \\
\hline 2 & $\begin{array}{l}\text { Menu data } \\
\text { kriteria }\end{array}$ & $\begin{array}{l}\text { Menampilkan } \\
\text { kriteria yang ada } \\
\text { di database }\end{array}$ & Tampil halaman kriteria & Sesuai \\
\hline 3 & $\begin{array}{l}\text { Menu input } \\
\text { kriteria }\end{array}$ & $\begin{array}{l}\text { Menginput } \\
\text { kriteria baru }\end{array}$ & $\begin{array}{l}\text { Menampilkan halaman input } \\
\text { kriteria }\end{array}$ & Sesuai \\
\hline 4 & $\begin{array}{l}\text { Menu data } \\
\text { alternatif }\end{array}$ & $\begin{array}{l}\text { Menampilkan } \\
\text { alternatif yang } \\
\text { ada pada } \\
\text { database }\end{array}$ & Tampil halaman alternatif & Sesuai \\
\hline 5 & $\begin{array}{l}\text { Menu input } \\
\text { alternatif }\end{array}$ & $\begin{array}{l}\text { Menginput } \\
\text { alternatif baru }\end{array}$ & $\begin{array}{l}\text { Menampilkan halaman input } \\
\text { alternatif }\end{array}$ & Sesuai \\
\hline 6 & $\begin{array}{l}\text { Menu hasil } \\
\text { seleksi }\end{array}$ & $\begin{array}{l}\text { Menampilkan } \\
\text { hasil seleksi } \\
\text { dengan metode } \\
\text { TOPSIS }\end{array}$ & $\begin{array}{l}\text { Menampilkan hasil perhitungan } \\
\text { dengan metode TOPSIS }\end{array}$ & Sesuai \\
\hline 7 & $\begin{array}{l}\text { Menu ubah } \\
\text { password }\end{array}$ & $\begin{array}{l}\text { Mengubah } \\
\text { padssword baru }\end{array}$ & $\begin{array}{l}\text { Menampilkan halaman untuk } \\
\text { mengubah password }\end{array}$ & Sesuai \\
\hline 8 & Menu logout & $\begin{array}{l}\text { Keluar dari } \\
\text { halaman admin }\end{array}$ & $\begin{array}{l}\text { Keluar dari halanab } \\
\text { administrator }\end{array}$ & Sesuai \\
\hline
\end{tabular}

\section{SIMPULAN (PENUTUP)}

Dapat diketahui bahwa metode topsis dapat menentukan peminatan jurusan pada SMA Negeri 1 Wonosari berdasarkan kriteria-kriteria yang ada. Sistem Pendukung Keputusan Peminatan Jurusan pada SMA Negeri 1 Wonosari Menggunakan Metode Topsis yang sudah di rekayasa dapat di implementasikan di SMA Negeri 1 Wonosari. Sehingga didapat bahwa logika flowchart perhitungan normalisasi dan perengkingan adalah benar dan pengujian black box yang meliputi uji input proses dan output dengan mengacu pada rancangan perangkat lunak yang sudah di buat telah terpenuhi sesuai dengan rancangan. 


\section{DAFTAR PUSTAKA}

[1] H. Hertyana, Analisa Penentuan Jurusan Pada SMA Kartika VII-1 mengggunakan Metode Fuzzy Inference System Mamdani. Jakarta, 2018.

[2] R. S. Putra, M. AR, and Bahrun, "STRATEGI PENINGKATAN MUTU PENDIDIKAN PADA SMA NEGERI 3 MEULABOH KECAMATAN JOHAN PAHLAWAN KABUPATEN ACEH BARAT," J. Adm. Pendidik., vol. 5, no. 3, pp. 161-166, 2017.

[3] D. L. Kurniasih, "istem Pendukung Keputusan Pemilihan Leptop Dengan Metode Topsis," J. Pelita Inform. Inf. dan Inform., 2013.

[4] K. D. Purwitasari and F. S. Pribadi, "Implementasi Sistem Pendukung Keputusan Peminatan Peserta Didik SMA menggunakan Metode AHP (Analytic Hierarchy Process) dan SAW (Simple Additive Weighting)," J. Tek. Elektro, vol. 7, no. 2, 2015.

[5] L. N. HIDAYAT, "METODE TOPSIS UNTUK MEMBANTU PEMILIHAN JURUSAN PADA SEKOLAH MENENGAH ATAS,” Semarang, 2014. 